\title{
NILAI-NILAI ISLAM DAN KERAGAMAN BUDAYA MELAYU DALAM SITUS WWW.MELAYUONLINE.COM
}

\author{
Eni Maryani ${ }^{35}$ dan Detta Rahmawan ${ }^{36}$, \\ Fakultas Ilmu Komunikasi Universitas Padjadjaran
}

\begin{abstract}
ABSTRAK
Sebagai salah satu negara di kawasan Asia Tenggara, saat ini penetrasi internet dan media digital di Indonesia telah berkembang dengansangat pesat. Beragam media digital seperti situs telah muncul dan menjadi sumber beragam informasi bagi khalayak, termasuk informasi tentang kebudayaan. Salah satu situs terkait budaya, terutama budaya melayu yang menarik diamati adalah melayuonline.com. Sebagai sebuah situs yang berorientasi pada konten-konten budaya, melayuonline.com telah hadir sejak tahun 2007 dengan tujuan melestarikan dan mengembangkan budaya melayu. Penggunaan berbagai bahasa asing selain Bahasa Indonesia memperlihatkan keragaman dan jangkauan luas situs ini. Sementara itu berdasarkan beragam kajian, dapat dikatakan bahwa Islam sebagai agama melekat dalam budaya melayu bahkan umumnya masyarakat menganggap ada yang menilai Islam melekat dalam budaya Melayu, dan dianggap sebagai dwi tunggal dalam arti tidak dapat dipisahkan. Oleh karena itu melalui etnografi virtual penelitian ini mengeksplorasi nilai-nilai islam dan keragaman budaya melayu dalam situs melayuonline.com. Untuk melakukan kajian enotgrafi virtual terhadap situs melayuonline.com, penelitian ini menempatkan melayuonline.com sebagai situs budaya. Penelitian ini menemukan bahwa Budaya melayu merupakan budaya yang dinamis dan mengalami beragam dialektika. Nilai-nilai islam mewarnai situs melayuonline.com melalui berbagai bentuk baik berbentuk symbol, visual, dan isi media. Budaya melayu secara virtual menampilkan keterikatan terhadap nilai-nilai islam baik dari segi isi maupun relasi. Cerita rakyat yang ditampilkan dalam melayuonline.com dapat menjadi cultural capital untuk menyebarluaskan nilai-nilai pluralisme yang dimililiki budaya melayu dan budaya lainnya di Indonesia. Selain itu, situs melayuonline.com juga mengembangkan nila-nilai pluralisme dalam Islam yang mewarnai kemajemukan dalam budaya melayu.
\end{abstract}

Kata kunci: Islam, Komunitas Online, Islam, Pluralisme, Budaya Melayu

\begin{abstract}
As one of the country in Southeast Asia, the state of Internet and digital media penetration in Indonesia has grown rapidly. Various digital media such as websites have emerged and become important source of information, including information about culture. Within this context, one of websites related to culture, especially Malay culture is Melayuonline.com. As a website which oriented to cultural content, melayuonline.com has been present since 2007 with the aim of preserving and developing Malay culture. The use of foreign languages other than Indonesian Language shows the diversity and wide reach of this site. Meanwhile, based on various studies, it can be said that Islam as a religion inherent in Malay culture and generally people think there is a view of Islam inherent in Malay culture, and considered as a single dual in the sense can not be separated. Therefore, through virtual etnography this research explores Islamic values and cultural diversity in the website melayuonline.com. This study found that Malay culture is dynamic and diverse. Islamic values in melayuonline.com can be seen throughout various forms, both from symbolic, text and visual
\end{abstract}

\footnotetext{
${ }^{35}$ Eni Maryani, Kepala Pusat Studi Media dan Budaya, Fikom Unpad email: eni.maryani@unpad.ac.id ${ }^{36}$ Detta Rahmawan, Staf Pengajar Program Studi Manajemen Komunikasi, Fikom Unpad email: detta@unpad.ac.id
} 
content. Virtually, Malay culture displays attachment and relations to Islamic values. The folklore shown in melayuonline.com can be a cultural capital to disseminate the values of pluralism that Malay culture and other cultures have in Indonesia.In addition, the site melayuonline.com also develops a pluralist view and values on Malay culture.

Keywords: Islam, Online Community, Pluralism, Islam, Malay Culture

\section{PENDAHULUAN}

Teknologi komunikasi internet yang berskala global dan mampu memfasilitasi berbagai proses komunikasi menjadi salah satu unsur penting dalam perkembangan budaya. Salah satu situs terkait budaya melayu yang menarik untuk diteliti adalah melayuonline.com. Sebagai sebuah situsbudaya, melayuonline.com telah hadir sejak tahun 2007. Dalam keterangan di situsnya, tujuan dari melayuonline.comadalah untuk melestarikan dan mengembangkan budaya melayu. Merujuk pada keberadaan melayuonline.com sebagai situs budaya, maka penelitian ini mengamati dan menganalisis keberadaan melayuonline.com dalam kajian komunikasi dan budaya. Indonesia sebagai masyarakat multikultur yang dapat dikatakan berbasis pada budaya melayu perlu mengetahui serta memahami nilainilai budaya melayu,oleh karena itu upaya melayuonline.com dalam menggali, menjaga dan mengembangkan budaya melayu menjadi penting.
MelayuOnline.com adalah sebuah situs yang berisikan beragam data dan informasi terkait dunia Melayu dan berbagai hal yang bersifat kemelayuan sedunia. Situs ini pertama kali muncul dalam dunia online pada tanggal 20 Januari 2007. Situs MelayuOnline.com dibuat dan dikelola oleh Balai Kajian dan Pengembangan Budaya Melayu (BKPBM). Balai Kajian dan Pengembangan Budaya Melayu adalah sebuah institusi non pemerintah yang berada di Yogyakarta, Indonesia. Institusi ini dibuat dan dikelola oleh masyarakat Melayu, dengan dana yang diperoleh secara swadaya dari pihak-pihak masyarakat Melayu dan pihak lain yang memiliki kepedulian terhadap pelestarian dan pengembangan budaya Melayu.

\begin{tabular}{|c|c|}
\hline BKРBM & sendiri \\
\hline beberapa tujuan & yang \\
\hline
\end{tabular}

MelayuOnline.com sebagai berikut:

"1. Menghidupkan kembali budaya Melayu bukan dalam arti kulturalisme sempit (primordialisme), namun justru 
sebagai perekat kehidupan berbangsa dan bernegara yang secara faktual terdiri dari sukubangsa dan budaya yang beraneka ragam.

2. Menggali, mengumpulkan dan memelihara berbagai peninggalan senibudaya Melayu sebagai

dokumentasi sejarah dan budaya.

3. Mengembangkan budaya Melayu agar sesuai dengan perubahan zaman, sehingga nilai-nilai luhur yang terkandung di dalamnya tetap dapat dipakai sebagai acuan berpikir dan berperilaku dalam menyikapi dinamika global.

4. Mengangkat peran perempuan Melayu dalam menjaga budaya yang selama ini belum banyak diungkap dan dipahami masyarakat.

5. Memberikan informasi dan pelayanan seluas-luasnya kepada masyarakat Melayu tentang segala sesuatu yang berkaitan dengan adat-istiadat dan seni-budaya Melayu.

6. Mempromosikan budaya Melayu kepada masyarakat luas, baik pada tingkat regional, nasional maupun internasional" (Al Mudra, n.d.)

Pembuatan melayuonline.com memperlihatkan bahwa BKPBM menggunakan teknologi komunikasi dan informasi, dalam bentuk pembuatan situs, yang bertujuan untuk melestarikan tradisi budaya melayu. Saat pertama kali diluncurkan pada tahun 2007, MelayuOnline.com dapat diakses dalam tiga bahasa, yakni bahasa Indonesia, bahasa Inggris, danbahasa Prancis. Saat ini berdasarkan lamannya, melayuonline.com sedang mengembangkan sebelasbahasa lainnya. Meskipun sebelas bahasa yang akan dikembangkan ini belum tersedia dengan sempurna, namun hal ini menunjukkan upaya untuk menyebarkan konten melayuonline.com ke dalam beragam bahasa agar lebih tersebar luas.

Upaya tersebut sejalan dengan perkembangan teknologi Internet yang memberikan akses dan kemampuan jangkauan khalayak seluas-luasnya, tidak terbatas oleh batasan geografis. Sehingga dapat dikatakan bahwa upaya ini dilakukan dalam rangka membangun sebuah komunitas virtual terkait kebudayaan melayu. Bahasa yang disediakan melayuonline.com memungkinkankonten mereka diakses dan dibaca tidak saja masyarakat melayu yang memiliki kemampuan Bahasa Indonesia yang berakar dari Bahasa melayu akan tetapi juga masyarakat melayu yang menggunakan Bahasa lain. Selain itu akses Bahasa yang beragam juga 
memungkinkan pemerhati budaya Melayu dari berbagai bangsa dalam memanfaatkan melayuonline.com sebagai sumber informasi, serta unttuk lebih mengetahui dan memahami budaya melayu. Berdasarkan beberapa paparan diatas, makaartikel ini mencoba untuk mengeksplorasi nilai-nilai islam dan keragaman budaya melayu dalam situs melayuonline.com

\section{KERANGKA PEMIKIRAN}

Dalam bukunya "The Network Society", Jan van Dijk mengemukakan bahwa perkembangan internet dapat dianggap sebagai "jalan tak kasat mata" (invisible roads) yang memungkinkan orang-orang untuk terhubung ke seluruh dunia dan membangun jaringan yang lebih besar di luar batasan fisik (van Dijk, 2006). Dalam lingkup dunia online, istilah "komunitas online" ataupun "komunitas virtual" dapat didefinisikan sebagai "[sebuah] asosiasi [atau perkumpulan] dari beberapa orang yang tidak terkait dengan waktu, tempat dan keadaan fisik atau material... yang diciptakan di lingkungan elektronik dengan bantuan komunikasi yang dimediasi" (ibid). Komunitas virtual juga dapat didefinisikan sebagai sekelompok orang yang menggunakan sistem computer (yang tersambung dengan jaringan internet) untuk berkomunikasi, berinteraksi dan berbagi minat yang sama dan menciptakan rasa kebersamaan melalui ritual, protocol...dan peraturan online mereka sendiri (Gallagher \& Savage, 2012).

Komunitas virtual online telah ada sejak dulu. Beberapa perintis komunitas virtual dalam kajian terkait komunitas virtual misalnya adalah "The Well", yang dimulai pada tahun 1985, dan newsgroup Usenet, dimulai pada tahun 1979, telah dikenal luas sebagai komunitas virtual pertama di Internet (Ridings \& Gefen, 2004). Howard Rheingold, salah seorang akademisi yang mengkaji komunitas virtual, menyatakan bahwa popularitas komunitas online juga terkait dengan "respon terhadap kebutuhan masyarakat yang terkait dengan disintegrasi masyarakat tradisional" (Rheingold, 1993). Ada berbagai jenis komunitas online dengan beragam bentuk seperti forum diskusi yang bersifat tradisional (Chiou \& Lee, 2008) situs jejaring sosial atau media sosial (Chapman \& Lahav, 2008), maupun komunitas kolaboratif seperti Wikipedia (Pfeil, Zaphiris, \& Ang, 2006). Komunitas virtual yang ada saat ini 
dapat memiliki perbedaan maupun persamaan antara satu sama lain.

Gunawardena dkk(2009) juga mengamati bahwa komunitas online seperti situs forum maupun situs jejaring sosial dapat mengarah pada pengembangan budaya yang seringkali baru dan terbentuk dari hasil interaksi anggota terhadap komunitas virtual mereka. Kerap ditemui bahwa mereka yang berkomunikasi secara online mengidentifikasi identitas mereka dengan beberapa kerangka referensi yang bersifat hibrid dan difasilitasi oleh Internet (Gunawardena, et al., 2009). Oleh karena itu, dapat dikatakan bahwa komunitas online dapat menawarkan apa yang disebut dengan "idioculture" atau pemahaman baru mengenai sebuah budaya yang terjadi karena interaksi yang dilakukan seseorang dalam sebuah komunitas virtual. Definisi idioculture sendiri misalnya dapat dilihat sebagai berikut: "[sebuah] Sistem pengetahuan, kepercayaan, perilaku, dan kebiasaan yang dipahami oleh anggota kelompok yang berinteraksi dengan anggota lain, yang dapat menjadi rujukan dan menjadi dasar interaksi lebih lanjut"(Cole, 2007).

Oleh karena itu dapat dikatakan bahwa konsep komunitas virtual dan idioculture dapat digunakan dalam menganalisis situs melayuonline.com sebagai sebuah sumber informasi budaya melayu, dan sekaligus juga menjadi wadah terbentuknya persepsi mengenai budaya melayu yang dibangun dalam sebuah komunitas virtual.

\section{METODE}

Penelitian ini menggunakan metode etnografi virtual(Hine, 2017) untuk melakukan analisis terhadap situs melayuonline.com sebagai situs budaya. Metode etnografi virtual dilakukan untuk melihat dan memahami secara detil, bagaimana situs melayuonline.com berkembang, membentuk sebuah komunitas virtual, dan menampilkan nilainilai kebudayaan melayu yang bersifat khas dan inklusif serta juga terkait dengan nilai-nilai pluralisme.Pengumpulan data dilakukan dengan beberapa cara yaitu; 1) melakukan pembahasan terkait berbagai lambang, simbol, dan tampilan visual lain yang ada dalam situs melayuonline.com; 2) Melakukan analisis isi secara kualitatif terhadap berbagai artikel yang ada, serta melakukan kategorisasi data untuk dapat memperkuat temuan penelitian. Dokumentasi dilakukan dengan melakukan screencapture baik terkait 
temuan visual maupun pendokumentasian artikel. Analisis data dilakukan secara tematis dengan menonjolkan beberapa kategori temuan yang memerlukan pembahasan secara mendalam.

\section{HASIL DAN PEMBAHASAN}

Melayuonline.com sebagai sebuah situs budaya dalam kajian etnografi virtual dilihat sebagai sebuah artefak budaya yang mengandung beragam nilai terkait dengan sebuah kebudayaan yang dibangun oleh masyarakat virtual.

\section{Representasi Identitas Keislaman dalam www.melayuonline.com}

Template dari sebuah situs adalah identitas utama yang dikonstruksi oleh komunitas virtual. Bagian ini akan selalu ditemukan di setiap halaman yang diakses khalayak ketika berkunjung ke situs tersebut. Oleh karena itu rancangan template merupakan representasi penting yang dapat secara intensif mengkostruksi identitas sebuah komunitas virtual.

Apabila kita melihat situs melayuonline.com maka pada bagian kiri atas kita akan menemukan sebuah kotak yang memuat gambar panorama laut yang memperlihatkan beberapa orang dalam perahu dengan latar belakang yang memperlihatkan separuh matahari kemerahan yang akan terbenam di laut. Dibagian tengah kotak tersebut terdapat grafis huruf arab dan dibawahnya tertulis nama situs www.melayuonline.com. Kotak ini merupakan salah satu identitas utama yang dikenalkan pada khalayak pengunjung situs.

Sementara itu dibagian tengah bagian atas situs ini ditemukan kalimat 'dunia melayu sedunia' dan dibawahnya kita juga akan menemukan tulisan 'melayu'dalam kata-kata melayuonline.com yang yang secara grafis menyerupai huruf arab. Selain itu dibagian bawah kotak memanjang yang berisi beragam halaman yang dimuat oleh situs melayuonline.com kita akan menemukan beragam versi bahasa yang disediakan untuk mengakses melayuonline.com dan bahasa arab menjadi salah satu yang digunakan atau disediakan.

Selanjutnya di bagian bawah ketersediaan Bahasa dalam situs melayuonline kita akan menemukan bagian awal dari halaman situs yang diunggah setiap hari. Bagian ini merupakan keterangan waktu dari tampilan komunitas virtualsetiap harinya. Keterangan waktu ini ditandai penanggalan dalam tahun masehi dan 
hijriyah. Selain itu, keterangan waktu untuk menandai banyaknya pengunjung dalam masehi dan hijriah juga digunakan situs tersebut.



Dibagian bawah situs terdapat Pengembangan Budaya Melayu" dan lambang dari Balai Kajian Budaya dibawahnya tercantum sebuah tulisan Melayu, berupa logo dan tulisan panjang dalam Bahasa Arab. bertuliskan "Balai kajian dan

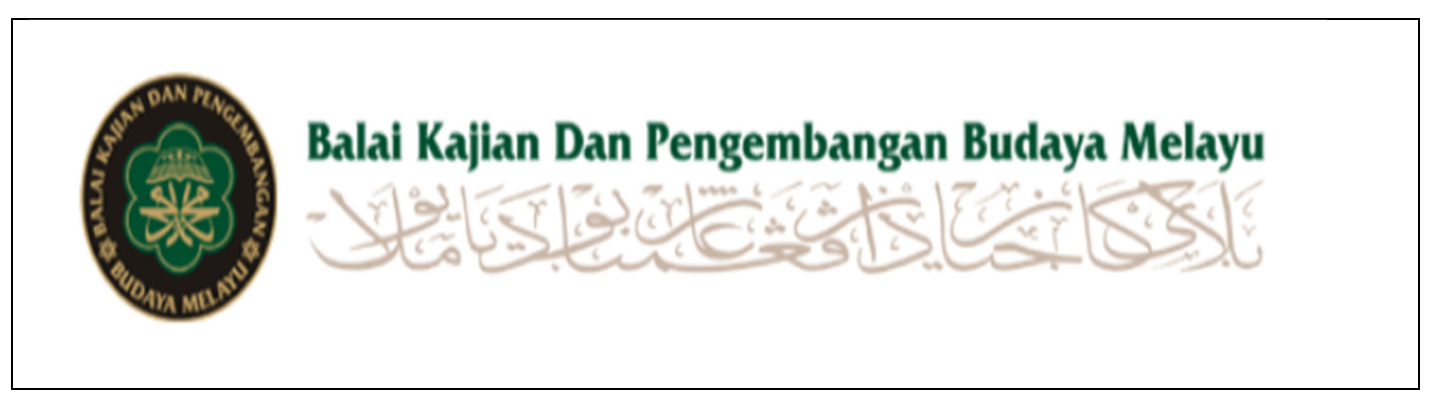

Representasi identitas Islam juga dapat dilihat dalam konten situs, seperti misalnya dalam artikel "Kedatangan Islam dan penyebarannya di Indonesia; suatu kajian lewat naskah melayu" (9 Desember, 2013) $)^{37}$. Artikel ini menjelaskan tentang masuknya Islam ke Indonesia yang

37

http://m.melayuonline.com/ind/article/read/1008/a disebarkan secara damai oleh para pedagang India. Tidak ada peperangan yang mewarnai masuknya Islam ke Nusantara dan artikel ini menegaskannya dengan kalimat 'Islam menyebar di kepulauan Indonesia secara damai, dari Kerajaan Pasai, setapak demi setapak di-indonesia-s3eng-s0-s2fr-s0- 
hingga dalam tujuh abad Islam telah menyebar ke seluruh pelosok Nusantara'. Selain itu tulisan ini juga menekankan kaitan erat antara masyarakat Melayu dengan kedatangan Islam seperti tertulis dalam artikel ini sebagai berikut 'pada masa-masa lampau kelompok etnis yang dipandang kuat sambutannya pada Islam adalah bangsa melayu'.

Nilai pluralisme muncul pada artikel "melayuonline.com mengawal pluralism". Artikel ini memaparkan bahwa 'saudarisadari kita warga Tionghoa tengah merayakan Hari Raya Imlek 2561'. Pengakuan terhadap keberadaan agama atau keyakinan kelompok lain di luar Islam juga ditegaskan dengan kalimat 'Sekali lagi Gong Xi fa Cai untuk warga Tionghoa. Semoga kita dapat menikmati kehidupan Indonesia yang lebih baik dan berkeadilan sosial bagi seluruh rakyat Indonesia'.Sebagai sebuah situs yang membangun identitas Islam dalam tampilannya, maka pandangan melayuonline.com terkait dengan pluralism menghasilkan konstruksi bahwa nilai-nilai pluralism juga dihargai oleh Islam dan umatnya.

Merujuk pada symbol dan tanda yang muncul dalam visual dan isi halaman depan atau template serta beberapa artikel yang diunggah di situs melayuonline.com maka dapat terlihat pandangan nilai-nilai Islam, pandangan pluralisme dalam Islam dan keberadaan Islam di Indonesia yang direpresentasikan.

\section{Kemajemukan Budaya Melayu dalam melayuonline.com}

Kemajukan budaya melayu dapat ditelusuri dari beragam aspek seperti pengertian, sejarah, artefak budayanya serta pandangan masyarakat tentang beragam aspek kehidupan. Kemajemukan tersebut ditampilkan dalaam laman melayuonline.com dalam beragam bentuk baik simbol, pemilihan tema tulisanmaupun cara pandang masyarakat yang dianggap berkaitan dengan beragam isu.

\section{Situs melayuonline.com dan}

\section{Keragaman Budaya}

Situs melayuonline.com memiliki berbagai macam dokumentasi, inventarisasi, dan penyajian informasi tentang berbagai hal terkait dunia Melayu dan kemelayuan yang dikumpulkan melalui berbagai sumber pustaka kemelayuan, media cetak serta media online yang berasal dari Indonesia maupun negara-negara lain. Tim pengelola 
melayuonline.com kemudian mengklasifikasi dan menyusun data yang telah diperoleh tersebut sembari tetap memperhatikan keabsahannya secara akademis. Keabsahan sumber dalam melayuonline.com diperhatikan dengan seksama. Hal ini berguna untuk membantu para pembaca situs ini dalam mengetahui dan memahami berbagai artikel yang ada dan menelusuri sumber asli artikel tersebut. Situs melayuonline.com memiliki dua puluh empat menu utama terkait dunia Melayu, yang bisa dilihat dalam beranda situs. Beberapa diantaranya adalah Berita; Artikel; Sejarah Melayu; Budaya Melayu; Sastra Melayu; Tokoh Melayu; Peneliti/Periset Melayu; Penghargaan; Direktori; Ensiklopedi Melayu; Kamus Melayu; Resensi Buku; Perpustakaan; Agenda; Pautan; Forum; Koleksi; Kedai; dll. Gambaran tersebut dapat langsung terlihat dalam tampilan lamannya berikut ini:

Beranda I Berita I Opini I Artikel I Sejarah Melayu I Budaya Melayu I Sastra Melayu I Tokoh Melayu I Peneliti Melayu I Penghargaan

Kamus Melayu I Ensiklopedi Melayu I Agenda I Direktori I Pautan I Forum I Resensi Buku I Perpustakaan I Koleksi I Kedai Komentar Tamu I Tentang Kami I Kerjasama I Hubungi Kami I Donasi I Peta Situs

Bahasa Indonesia | English | Erançais | Thailand I Filipino | Nederlands | Italiano | Arabic | Deutsch | Español | Burmese | Khmer

Sebagai sebuah situs yang padat dan berisikan berbagai data, informasi, berita, dan kajian mengenai dunia Melayu, melayuonline.com juga menekankan pentingnya kontribusi dari para pembacanya, salah satunya adalah kontribusi dari data-data pembaca dengan cara bergabung untuk masuk ke dalam keanggotaan. Para pembaca situs ini yang ingin menelusuri lebih dalam perihal dunia kemelayuan dan juga selalu mendapatkan informasi terkini dari melayuonline.com dapat mendaftar dan menjadi anggota dari melayuonline.com. Selain itu, melayuonline.com juga membuka diri bagi orang-orang yang ingin menyumbangkan beragam artikel untuk kemudian dapat dimuat di situs ini, tentunya setelah melalui tahapan penyeleksian dari tim pengelola. Oleh karena itu dapat disimpulkan bahwa melayuonline.com berjuang untuk tidak hanya sekadar menjadi portal berita saja, namun mereka juga ingin membentuk sebuah komunitas yang bersifat virtual.

\section{Konsep Melayu Menurut} melayuonline.com

$\begin{array}{ccr}\text { Salah } & \text { satu } & \text { laman } \\ \text { melayuonline.com } & \text { yang } & \text { berjudul }\end{array}$ 'Pertanggungjawaban Akademis' MelayuOnline memuat sebuah tinjauan akademis yang menarik mengenai sudut 
pandang komunitas ini terkait dengan definisi dari "Melayu". Dalam laman ini, pertama-tama dipaparkan beberapa pandangan mengenai definisi "Melayu" dari beberapa ilmuwan seperti yang terkait denganpembagian melayu dalam tiga kategori yaitu terkait dengan ras, suku bangsa, dan dalam pengertian suku atau etnis (Lutfi, 1986). Kemudian dipaparkan juga pendapat yang mengemukakan beberapa syarat agar seseorang dapat menjadi Melayu, terkait dengan agama Islam, Bahasa melayu, menggunakan adat istiadat melayu dan juga menetap di kawasan melayu (Sinar, 1987). Selanjutnya, dikemukakan pulapandangan yang menggunakan fakta sejarah terkait tiga tahapan migrasi ras terkait cikal bakal masyarakat Melayu Nusantara (Melalatoa, 1986). Adapula pendekatan yang lebih bersifat genealogis dalam melihat melayu menekankan kedekatan budaya Melayu dengan budaya Arab (Ambary, 1986).

Selain dari beberapa tinjauan akademik yang dikemukakan di atas, pihak melayuonline.com sendiri menawarkan perspektif yang dimilikinya terkait dengan Melayu, dan menekankan tentang perlunya pemaknaan mengenai kemelayuan dalam perspektif yang lebih inklusif, seperti dijelaskan dalam argumen sebagai berikut:

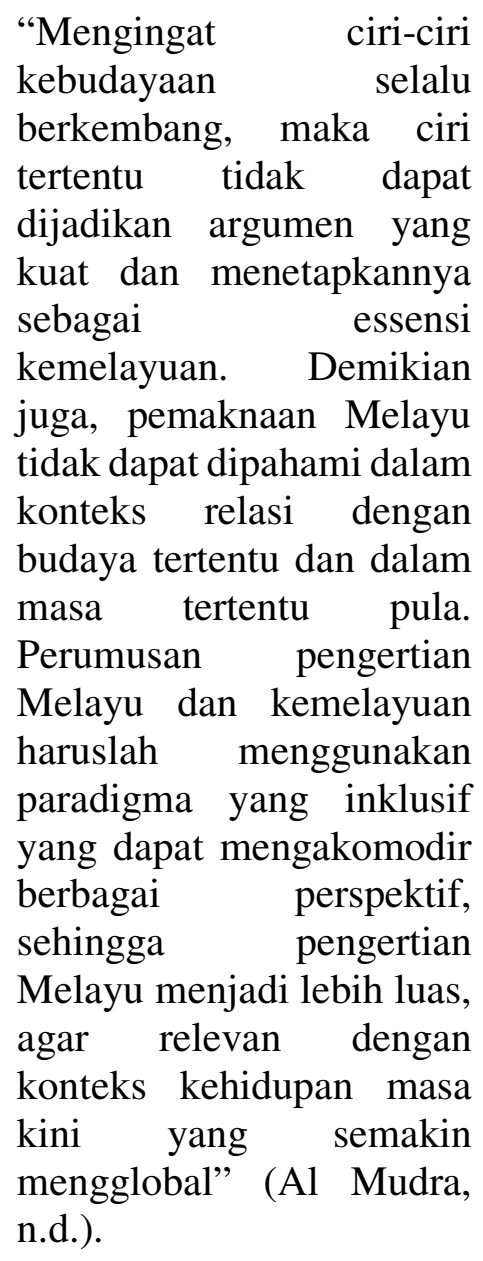

Lebih jauh, pihak melayuonline.com mengemukakan bahwa mereka memaknai istilah "Melayu" sebagai sebuah budaya yang inklusif dan bukan dalam artian sempit terkait suku, etnis, atau entitas budaya lainnya. Dengan pengertian melayu seperti yang ditawarkan oleh melayuonline.com, mereka merangkul setiap orang, komunitas, masyarakat, yang ada di berbagai tempat, di belahan dunia 
manapun yang masih atau pernah menjalankan tradisi dan kebudayaan Melayu. Mereka berpendapat bahwa di berbagai belahan dunia selalu ada pemahaman baru, dan juga perkembangan tradisi dan budaya melayu terjadi interaksi antara masyarakat Melayu dengan lingkungan tempat tinggal ataupun masyarakat luar lainnya.

Menurut pihak melayuonline.com, masyarakat Melayu di seluruh dunia pada dasarnya memiliki akar sejarah dan budaya yang sama. Namun keragaman afiliasi pada sistem sosial, politik, dan agama dapat memunculkan berbagai definisi tentang Melayu yang berbedabeda. Misalnya saja, dalam pandangan masyarakat pada umumnya, budaya Melayu memiliki keterkaitan yangsangat erat dengan agama Islam. Tentu saja pandangan ini tidak salah, namun dapat pula dilihat dari perspektif lain karena pandangan ini "membatasi pemaknaan Melayu pada fase sejarah tertentu, yaitu fase Islam [dan]memutus mata rantai sejarah Melayu yang membentang baik sebelum maupun setelah perkembangan Islam” (Melayu Online, n.d.). Oleh karena itu, pemaknaan mengenai Melayu yang ditawarkan oleh melayuonline.com bersifat lebih luas, dan bertujuan untuk menumbuhkan pemahaman dan kesadaran bahwa identitas kemelayuan "bukan merupakan ikatan sempit berdasarkan darah keturunan (genealogis), persamaan ras atau agama, tetapi lebih pada suatu ikatan kultural (cultural bondage)" (ibid.). Pemahaman seperti ini memperlihatkan pandangan inklusif dan pluralis pihak melayuonline.com dalam membangun komunitas virtualnya.

Pandangan melayuonline.com dipaparkan dalam beberapa tulisan terkait dengan sejarah melayu. Pada tulisan ini diawal kalimatnya sudah ditegaskan betapa luasnya sejarah melayu dengan kalimat awal "Sejarah melayu mencakup dimensi yang luas dan rentang masa yang panjang". 
Beranda I Berita I Opini I Artikel I Sejarah Melayu I Budaya Melayu I Sastra Melayu I Tokoh Melayu I Peneliti Melayu I Penghargaan

Kamus Melayu I Ensiklopedi Melayu I Agenda I Direktori I Pautan I Forum I Resensi Buku I Perpustakaan I Koleksi I Kedai

Komentar Tamu I Tentang_Kami I Kerjasama I Hubungi Kami I Donasi I Peta Situs

Bahasa Indonesia I English I Erançais I Thailand I Eilipino I Nederlands I Italiane I Arabic I Deutsch I Español I Burmese I Khmer

Sabtu, 2 September 2017 I Ahad, 10 Dzulhijah 1438 H

Search

Advanced Search $x$

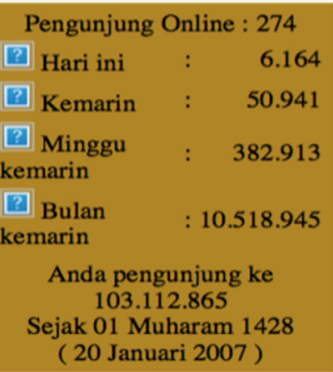

\section{Sejarah Melayu}

Beranda $>$ Sejarah Melayu

\section{Sejarah Melayu}

Sejarah Melayu mencakup dimensi yang luas, dengan rentang masa yang panjang. Jika Kerajaan Kuta dianggap sebagai kerajaan tertua dalam kebudayaan Melayu, maka awal fase sejarah Melayu adalah sekitar abad ke-4 atau 5 M. Sejarah yang dimaksud di sini adalah kejadian atau peristiwa yang benar-benar terjadi di masa lampau. Jejak-jejaknya dapat dilacak melalui peninggalan sejarah, baik berupa manuskrip, prasasti, sejarah lisan maupun artefak. Dalam portal ini, sejarah Melayu tersebut dibagi dalam tiga kategori: (1), sejarah tentang kerajaan, (2), naskah sejarah dan (2), peninggalan sejarah di situs sejarah, seperti candi, masjid, istana maupun makam.

Sementara terkait dengan budaya melayu, melayuonline menegaskan budaya melayu merujuk pada definisi kebudayaan yang diartikan sebagai "system terintegrasi di masyarakat yang berkaitan dengan nilai, kepercayaan, perilaku dan artefak...Kebudayaan melayu yang dibahas dalam portal ini tidak terlepas dari unsur-unsur yang telah didefenisikan di atas"(Melayu Online, n.d.). Selanjutnya laman ini juga merinci unsur-unsur kebudayaan yang universal yang dijadikan dasar mereka untuk menghimpun budaya melayu dalam beragam unsurnya yaitu pandangan hidup, kesenian, sastra, kuliner, upacara adat, peralatan (teknologi), artefak, Bahasa, bangunan, pengobatan tradisional dan hukum adat melayu.

Terkait dengan ciri khas budaya melayu adalah banyaknya nasehat dalam bentuk pantun yang kemudia menjadi quote setiap hari di laman melayuonline.com. Rangkaian pantu yang dunggah setiap hari itu dinamakan "Selaksa Pantun Melayu". Diantara pantun-pantun yang diunggah tampak pada screenshot berikut ini;

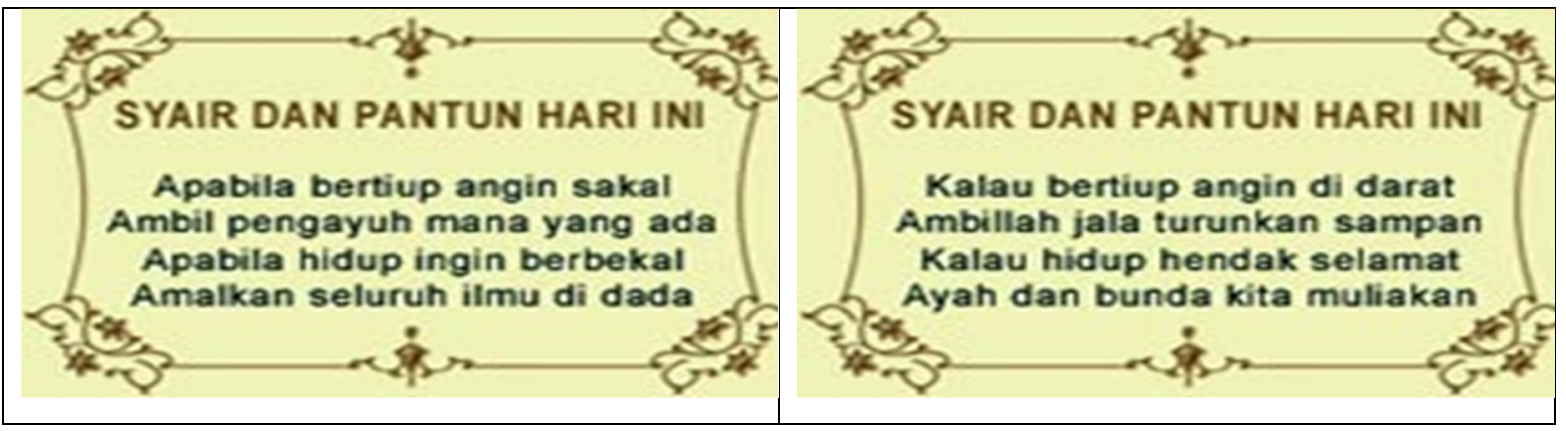




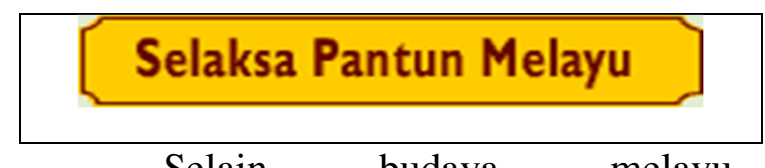

Selain budaya melayu, melayuonline.com juga memberikan pandangan tentang pihak-pihak yang disebut dengan tokoh melayu. Berdasarkan konsep yang dirujuk maka melayuonline mengunggah para tokoh melayu yang tersebar di bebrbagai negara seperti Indonesia, Malaysia, Singapura, Brunei Darusallam, Philipina, China, Taipei dan Afrika Selatan. Mereka juga melakukan pembaharuan informasi terkait dengan tokoh-tokoh melayu. Di dalam paparan mereka tentang tokoh melayu selain menyampaikan profil tokoh mereka juga menampilan pemikiran dan karyakarya tokoh tersebut terkait dengan nilainilai atau berbagai produk budaya melayu. Terkait dengan tokoh melayu dari Indonesia terdapat dua puluh dua daerah yang dijadikan keterangan daerah asal para tokoh melayu baik yang masih hidup maupun yang sudah meninggal. Daerah itu mencakup Aceh, Sumatera Utara, Sumatera Barat, Riau, Kepulauan Riau, Sumatera Selatan, Bengkulu, Jambi, Lampung, Bangka Belitung, Kalimantan Barat, Kalimantan Tengah, Kalimantan Selatan,Kalimtantan Timur. Sulawesi Utara, Sulawesi Tengah, Sulawesi
Tenggara, Sulawesi Selatan, Nusa Tenggara barat, Nusa Tenggara Timur, Maluku, dan berbagai daerah lainnya.

Berdasarkan data di laman melayuonline.com diketahui bahwa tokoh melayu di Indonesia berasal dari dua puluh dua daerah di Indonesia dan tersebar dari wilayah Barat (Aceh) sampai dengan wilayah Timur Maluku. Merujuk data tersebut maka terlihat bahwatokoh-tokoh budaya melayu telah berkembang di berbagai daerah Indonesia sejalan dengan perkembangan budaya melayu itu sendiri. Selain itu dapat dikatakan bahwa tokohtokoh melayu secara keseluruhan juga tersebar di berbagai negara Asia maupun Afrika. Hal ini menunjukkan bahwa tokoh-tokoh budaya melayu merupakan tokoh budaya yang sudah melewati batasbatas negara bahkan benua.

\section{Pemikiran tentang Pluralisme di melayuonline.com}

Kemajukan suatu budaya dapat dianalisis dari pemikiran mereka tentang keberagaman itu sendiri. Terkait dengan keberagaman atau paham pluralisme maka peneliti menganalisis berbagai pemikiran ataupun isu yang diangkat oleh melayuonline.com terkait dengan isu-isu tersebut. 
Salah satu tulisan Mahyudin Al Mudra yang dimuat dalam melayuonline.com berjudul 'Mewariskan Cerita Rakyat Nusantara di Tengah Pluralisme Budaya' (6 Desember 2008) ${ }^{38}$. melayuonline.com memiliki pemikiran bahwa salah satu sumber nilai-nilai budaya termasuk pluralisme dalam budaya melayu dapat dikembangkan melalui cerita-cerita rakyat.

Berdasarkan tulisan tersebut maka
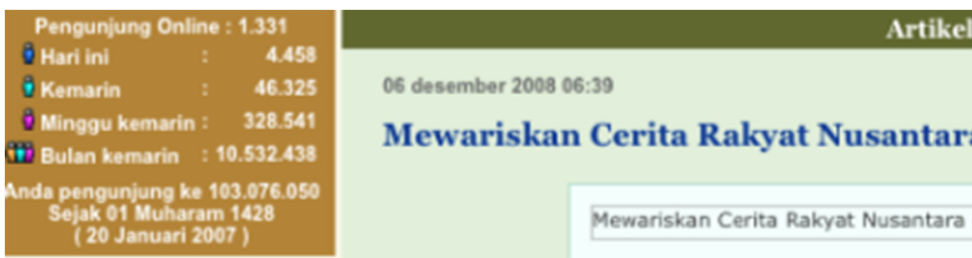

Mewariskan Cerita Rakyat Nusantara di Tengah Pluralisme Budaya

Mewariskan Cerita Rakyat Nusantara di Tengah Pluralisme Budaya

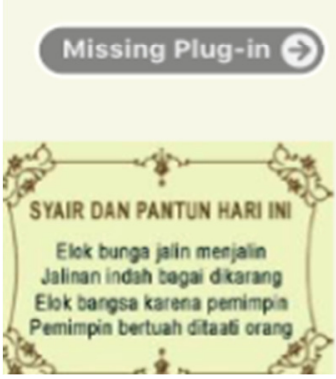

Oleh Mahyudin AI Mudra, SH., MM.

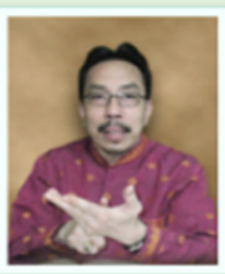

Para pendahulu setiap masyarakat di manapun selalu menanamkan nilainilai dan konsepsi-konsepsi yang kemudian diyakini sebagai blue-print yang menjadi penuntun dalam perjalanan hidupnya. Nilai dan konsepsi itu menjadi pedoman dalam tingkah laku. Tingkah laku setiap individu dan kelompok dan ekspresi-ekspresi simbolik mereka telah banyak diteliti oleh para ahli ilmu-ilmu sosial untuk melihat lebih jauh proses dan tujuan pewarisan nilai dan konsepsi tersebut dilakukan. Clifford Geertz mengatakan bahwa sistem pewarisan konsepsi dalam bentuk simbolik merupakan cara bagaimana manusia dapat berkomunikasi, melestarikan, dan mengembangkan pengetahuan dan sikapnya terhadap kehidupan (Geertz, 1973: 89).

\section{Didalam tulisannya Mudra}

merujuk pada pemikiran Claude Levi Strauss, yang memaknai bahwa cerita rakyat (sebagai sebuah mitos) yang tidak harus dipertentangkan dengan sejarah atau kenyataan. Levi Strauss memaknai mitos sebagai ekspresi atau perwujudan dari keinginan-keinginan masyarakat yang tidak disadari, tidak konsisten, tidak sesuai dengan kenyataan sehari-hari. Akan tetapi disisi lain Mudra berpendapat dari berbagai cerita rakyat yang ditemukan di
Aceh, Riau, Jawa, Kalimanta, Maluku atau

Papua memiliki kesamaann misalnya serita tentang keberadaan bidadari. Begitu pula cerita tentang anak durhaka yang dikenal dengan cerita Maling Kundang dari Sumatera barat ternyata juga ditemukan di Bangka Belitung, Kalimantan Barat, Sulawesi dan daerahdaerah nusantara lainnya (Mudra, 2006). Artinya sebagai mitos ternyata cerita rakyat di Nusantara memiliki kesamaan akan nilai-nilai yang dianut oleh masing-

\footnotetext{
${ }^{38} \mathrm{http}: / / \mathrm{melayuonline.com} / \mathrm{ind} / \mathrm{article} / \mathrm{read} / 841 / \mathrm{me}$ wariskan-cerita-rakyat-nusantara-di-tengahpluralisme-budaya.
} 
masing masyarakat di berbagai daerah. Artinya adanya pemahaman bersama tentang nlai-nilai yang dimiliki masyarakat lainnya atau terjadi pemahaman lintas budaya antara beragam masyarakat. Pemahaman ini kemudian diasumsikan dapat menjadi alat untuk mengembangkan solidaritas dan saling menghargai bahkan saling memiliki. Inilah yang dapat dijadikan modal bangsa indonesia untuk membangun konsep pluralismenya.

\section{Pemikiran-pemikiran tersebut} pada akhirnya mengembangkan sebuah wacana untuk memanfaatkan cerita rakyat dalam budaya melayu sebagai sarana untuk terus mengembangkan nilai-nilai solidaritas, saling memahami dan menghargai dalam masyarakat Indonesia yang multikultur. Akan tetapi agar nilainilai yang terkandung dalam berbagai cerita rakyat yang berkembang dalam budaya melayu terus dapat dicerna oleh generasi-generasi selanjutnya maka perlu dilakukan revitalisasi cerita rakyat untuk memberi pemahaman tentang pluralisme dalam budaya melayu. Cerita rakyat harus

39

http://melayuonline.com/ind/news/read/10536/bpk bm-dan-melayuonline.com-mengurai-melayudiaspora-dan-pluralitas. terus dikembangkan dan disesuaikan dengan kondisi dan situasi masyarakat sehingga dapat melintasi batasan ruang dan waktu.

Selain pemikiran tentang cerita rakyat terkait dengan upaya mewariskan nilai-nilai pluralism, melayuonline.com juga tidak mengabaikan keberadaan Diaspora dalam masyarakat Melayu. Pengertian Dasporamerujuk kepada bangsa atau penduduk etnis manapun yang terpaksa atau terdorong untuk meninggalkan tanah air etnis tradisional mereka; penyebaran mereka di berbagai bagian lain dunia, dan perkembangan yang dihasilkan karena penyebaran dan budaya mereka (Ember, Ember, \& Skoggard, 2005) Perhatian mereka terhadap keberadaan Diaspora masyarakat melayu dan Pluralitas dilakukan dengan memuat tukisan berjudul "BPKBM dan MelayuOnline.com Mengurai Melayu, Diaspora dan Pluralitas"39. Ketegasan posisi melayuonline terhadap pluralism juga ditegaskan dalam sebuah artikel berjudul "MelayuOnline.com Mengawal Pluralisme" ${ }^{40}$. Melalui tulisan ini dapat

40

http://melayuonline.com/ind/opinion/read/360/mel ayu-online.com-mengawal-pluralisme 
dimakani upaya untuk menjelaskan upaya budaya melayu menjaga dan mengembangkan pluralism dalam berbagai artefak budayanya termasuk situs www.melayuonline.com sebagai representasi masyarakat dan budaya melayu.

\section{SIMPULAN}

Melalui etnografi virtual, penelitian ini menemukan bahwa budaya melayu merupakan budaya yang dinamis dan mengalami beragam dialektika. Budaya melayu yang coba ditampilkan oleh situs melayuonline.com memiliki berbagai hal yang menarik untuk diamati terkait dengan konsep islam, kemajemukan budaya melayu serta nilai pluralisme. Nilai-nilai Islam mewarnai situs melayuonline.com melalui berbagai bentuk baik simbol, visual, serta isi media. Sebagai sebuah situs budaya, Melayuonline.com banyak mengangkat isu maupun pemikiran yang mengandung nilai-nilai pluralisme dalam kemajemukan budaya Melayu. Cerita-cerita rakyat dari masyarakat melayu di berbagai daerah di Indonesia memiliki kesamaan terkait dengan nilai-nilai dalam masyarakatnya sehingga dapat menjadi cultural capital (modal budaya) untuk membangun pemahaman lintar budaya dalam masyarakat multikultur di Indonesia.

Sebagai sebuah situs yang telah hadir sejak tahun 2007 dan berorientasi pada konten-konten budaya, secara tegas melayuonline.com menyatakan tujuannya dalam melestarikan dan mengembangkan budaya melayu. Berbagai konten yang ada dalam situs ini juga dapat dikatakan memiliki sumber akademik yang terpercaya dan dapat dijadikan sebagai bahan rujukan bagi pembacanya. Melalui hasil analisis yang telah dilakukan, terlihat bahwa secara konsisten melayuonline.com memperlihatkan ragam nilai-nilai islam dan keragaman budaya melayu serta nilai pluralisme yang sangat kental mewarnai isi situsnya. 


\section{DAFTAR PUSTAKA}

Al Mudra, M. (n.d.). Diambil dari melayuonline.com:

http://melayuonline.com/ind/about/dig/ 9/balai-kajian-dan-pengembanganbudaya-melayu

Ambary, M. H. (1986). Islam dan Sejarah Melayu: Pengamatan dari Data Arkeologi. In Masyarakat Melayu Riau dan Kebudayaannya. Pekanbaru: Pemerintah Propinsi Daerah Tingkat I Riau.

Chapman, C. N., \& Lahav, M. (2008). International ethnographic observation of social networking sites. $\mathrm{CHI}$ ' 08 extended abstracts on human factors in, computing systems, 3123-3128. Diambil dari http://dx.doi.org/10.1145/1358628.135 8818.

Chiou, J. S., \& Lee, J. (2008). What do they say about "Friends"? A cross-cultural study on Internet discussion forum. Computers in Human Behavior, 24(3), 1179-1195.

Cole, M. \&. (2007). Cultural-Historical Approaches to Designing for Development. In J. \&. Valsiner (Ed.), The Cambridge Handbook of Sociocultural Psychology. New York: Cambridge University Press.

Ember, M., Ember, C. R., \& Skoggard, I. (Eds.). (2005). Encyclopedia of Diasporas: Immigrant and Refugee Cultures Around the World. Volume I: Overviews and Topics; Volume II: Diaspora Communities. New York: Springer.

Gallagher, S. E., \& Savage, T. (2012). Crosscultural analysis in online community research: A literature review. Computers in Human Behavior. doi:10.1016/j.chb.2012.09.011

Gunawardena, C. N., Hermans, M. B., Sanchez, D., Richmond, C., Bohley, M., \& Tuttle, R. (2009). A theoretical framework for building online communities of practice with social networking tools. Educational Media International, 46(1), 3-16.
Hine, C. (2017). FROM VIRTUAL ETHNOGRAPHY TO THE EMBEDDED, EMBODIED, EVERYDAY INTERNET. In L. Hjorth, H. Horst, A. Galloway, \& G. Bell (Eds.), THE ROUTLEDGE COMPANION TO DIGITAL ETHNOGRAPHY (pp. 21-28). New York: Routledge.

Lutfi, M. (1986). Interaksi Antara Melayu dan Non Melayu Serta Pengaruhnya Terhadap Pembauran Kebudayaan dan Pendidikan. In Masyarakat Melayu Riau dan Kebudayaannya. Pekanbaru: Pemerintah Propinsi Daerah Tingkat I Riau.

Melalatoa, J. M. (1986). Tinjauan tentang Porsi Suku Bangsa di Propinsi Riau Masa Kini: Satu Hasil Proses Perkembangan. In Masyarakat Melayu Riau dan Kebudayaannya. Pekanbaru: Pemerintah Propinsi Daerah Tingkat I Riau.

Melayu Online. (n.d.). Pertanggung Jawaban Akademis MelayuOnline. Diambil dari melayuonline.com:

http://melayuonline.com/ind/about/dig/ 2/pertanggungjawaban-akademismelayuonline

Pfeil, U., Zaphiris, P., \& Ang, C. S. (2006). Cultural Differences in Collaborative Authoring of Wikipedia. Journal of Computer-Mediated Communication, 12(1), 88-113. Diambil dari http://dx.doi.org/10.1111/j.10836101.2006.00316.x

Rheingold, H. (1993). The virtual community: Homesteading on the electronic frontier. Reading, MA: AddisonWesley.

Ridings, M. C., \& Gefen, D. (2004). Virtual Community Attraction: Why People Hang Out Online. Journal of Computer-Mediated Communication, 10(1).

Sinar, L. T. (1987). Jati Diri. In S. L. Wan (Ed.), Kebudayaan Melayu Sumatera Timur. Medan: Universitas Sumatera Utara Press.

van Dijk, J. A. (2006). The Network Society (2nd ed.). London: SAGE Publications Ltd. 